\title{
Is fast-food consumption a problem among adolescents in Malaysia? An analysis of the National School-Based Nutrition Survey, 2012
}

Cheong Siew Man ${ }^{1 *}$, Lim Kuang Hock², Chan Ying Ying ${ }^{3}$, Kee Chee Cheong ${ }^{4}$, Lim Kuang Kuay ${ }^{5}$, Teh Chien Huey ${ }^{6}$, Azli Baharudin ${ }^{1}$ and Nur Shahida Abdul Aziz ${ }^{1}$

\begin{abstract}
Background: Fast-food consumption is an unhealthy dietary behaviour because it increases the risk of diet-related chronic diseases. We aimed to investigate factors associated with fast-food consumption, namely sociodemographic characteristics, body mass index-for-age, meal away from home habit, and intake of various food groups among adolescents in Malaysia.
\end{abstract}

Methods: We analysed data from the National School-Based Nutrition Survey (NSNS). The NSNS was a nationwide, crosssectional survey. Multiple-stage stratified cluster random sampling method was applied to obtain a representative sample of adolescents' population. This study recruited adolescents aged 10-18 years who were attending schools. Pre-tested selfadministered questionnaires in Malay language were used to obtain relevant information. Frequency of fast-food consumption per week was classified into three groups: "consumed fast-food four to seven days", "consumed fast-food one to three days", and "did not consume fast-food". Intake of food groups was assessed by self-administered food frequency questionnaire. Descriptive and complex sample multinomial logistic regression analyses were performed in data analysis.

Results: A total of 26,383 from 40,012 selected adolescents completed all the relevant questions for this study. Of those surveyed, $13.5 \%$ of the respondents consumed fast-food 4 to 7 days, $69.3 \%$ of the respondents consumed fast food 1 to 3 days, and $17.2 \%$ of them did not consume fast-food in a typical week. Frequency of fast-food consumptions (4 to 7 days and 1 to 3 days per week) was significantly associated with age; sex; ethnicity; locality of schools; frequency of eating out; and not consuming recommended intake of cereals or grains, vegetables, and meat or poultry or eggs.

Conclusion: In conclusion, age; sex; ethnicity; locality of schools; frequency of eating out per week; imbalanced intake of cereals or grains, meat, or poultry or eggs; and inadequate vegetable intake were significantly associated with fast-food consumption among adolescents in Malaysia. The findings of this study will be useful for policy makers in promoting healthy food choices among adolescents in Malaysia.

Keywords: Fast-food intake, Schooling adolescents, Healthy food choices, Dietary habit

\footnotetext{
* Correspondence: smcheong@moh.gov.my

'Centre for Nutrition Epidemiology Research, Institute for Public Health,

National Institutes of Health, Ministry of Health Malaysia, No.1, Jalan Setia Murni U13/53, Section U13, Setia Alam, 40170 Shah Alam, Selangor, Malaysia

Full list of author information is available at the end of the article
}

C C The Author(s). 2021 Open Access This article is licensed under a Creative Commons Attribution 4.0 International License, which permits use, sharing, adaptation, distribution and reproduction in any medium or format, as long as you give appropriate credit to the original author(s) and the source, provide a link to the Creative Commons licence, and indicate if changes were made. The images or other third party material in this article are included in the article's Creative Commons licence, unless indicated otherwise in a credit line to the material. If material is not included in the article's Creative Commons licence and your intended use is not permitted by statutory regulation or exceeds the permitted use, you will need to obtain permission directly from the copyright holder. To view a copy of this licence, visit http://creativecommons.org/licenses/by/4.0/ The Creative Commons Public Domain Dedication waiver (http://creativecommons.org/publicdomain/zero/1.0/) applies to the data made available in this article, unless otherwise stated in a credit line to the data. 


\section{Introduction}

Fast food is defined as "hot food such as hamburgers that is quick to cook or is already cooked and is therefore served very quickly in a restaurant" [1]. The fast-food industry has spread the fast-food culture worldwide: fastfood outlets and vendors have managed to expand in both developed and developing countries despite the increasing awareness of the adverse health effects associated with a diet high in fat, salt, and sugar. Over the past three decades, rapid economic development, urbanisation, and the influence of Western cultures have drastically changed the lifestyles of Malaysians. Malaysia first saw marked changes in dietary habits because of its rapid economic growth and changes in occupational patterns in the 1980s [2], which led the fast-food industry to experience heavy growth in the 1990s [3]. In the 2000s, the Department of Statistics Malaysia found that the number of fast food restaurants in Malaysia increased from 1621 in 2010 to 2597 in 2015 [4].

Adolescents who consumed unhealthy diet such as higher energy-dense food and inadequate intake of fruits and milk were more likely to consume fast-food frequently [5]. Poor dietary habits among adolescents can lead to excessive weight gain and increase the risk of obesity in adulthood because dietary habits that are established during adolescence could persist to adulthood $[6,7]$. Relevant literature from other countries revealed that fast-food consumption is prevalent in younger people, higher household income groups, adults with higher body mass index (BMI), and men [8-10]. In China, prevalence of fast-food consumption among Chinese adolescents aged 13-17 years increased rapidly from 17.9 to $26.3 \%$ between 2004 and 2009 [11]. Therefore, it would be interesting to investigate fast-food consumption pattern among adolescents in Malaysia.

Despite growing evidence of the increasing trend in fast-food consumption among adolescents, majority of the fast-food consumption studies in Malaysia were mainly conducted among children and adults [12, 13]. Moreover, local and national studies that examine the factors associated with fast-food consumption among adolescents are scarce. To the best of our knowledge, there was only one study that described fast-food intake habit among children aged 2 to 12 years old with responses from caregivers or parents. The study reported that $9.7 \%$ children in Malaysia ate fast-food at least once a week [13]. Therefore, the present study aims to investigate the factors associated with fast-food consumption in terms of sociodemographic characteristics, locality of schools, BMI, frequency of eating out, and intake of various food groups among adolescents in Malaysia. The findings of this study are essential for providing supporting data to policy makers and relevant government agencies in promoting healthy eating habit among adolescents.

\section{Methodology}

\section{Data sources}

Data from the National School-Based Nutrition Survey (NSNS) was used for the present analysis. The NSNS was a sub survey of the 2012 National School-Based Health Survey (NSHS) in Malaysia [14]. This nationwide survey was conducted from February to April 2012. Multiple-stage stratified cluster random sampling was used to obtain a representative sample of adolescents aged 10-18 years from all states in Peninsular and East Malaysia. The sampling frame consisted of all primary and secondary schools under the Ministry of Education Malaysia. The first stage of sampling was a selection of schools with probability proportional to school enrolment size nationwide. In total, 234 schools were selected to participate in this study. The second stage of sampling was random selection of classrooms from each selected school. The third stage of sampling was random selection of students from each selected class to provide information on intake of various food groups by answering a food frequency questionnaire (FFQ). All students in the selected classrooms were given informed consent forms prior to recruitment into this study. Parents or caregivers of primary school students were given consent forms, and secondary school students were given selfadministered assent forms. A total of 40,011 selected adolescents participated in the NSNS with a student response rate of $90.5 \%$. Only 26,588 respondents were randomly selected to answer the FFQ in order to provide information on intake of various food groups. As a result of the selection, 26,383 students completed FFQ with the response rate of $99.2 \%$.

\section{Variable definitions}

Frequency of fast-food consumption was assessed using the question, "Normally, how many days in a week do you eat fast food which was bought from fast-food restaurants, such as burgers, pizza, hotdogs, nuggets, fried chicken, French fries, and other similar things?" The answers provided by the respondents ranged from 0 to 7 days. The dependent variable was classified into three categories which were adolescents who consumed fast food 4 to 7 days, adolescents who consumed fast food 1 to 3 days, and adolescents who did not consume fast food in a week.

The independent variables were age, sex, locality of schools, ethnicity, weight status, frequency of eating out per week, and intake of food groups per day. Age was grouped as $10-12$ years, $13-15$ years, and $16-18$ years. Locality of schools was determined according to the geographical areas in both Peninsular Malaysia (Northern Zone, Central Zone, Southern Zone, and East Coast) and East Malaysia. The Northern Zone included the states of Perlis, Kedah, Pulau Pinang, and Perak. States 
in the Central Zone were Selangor, Putrajaya Federal Territory, and Kuala Lumpur Federal Territory. The Southern Zone consisted of Malacca, Negeri Sembilan, and Johor. The East Coast comprised of the states of Pahang, Terengganu, and Kelantan. Finally, East Malaysia was the states of Sabah and Sarawak. Ethnicities in Malaysia were grouped into Malay, Chinese, Indian, Indigenous from East Malaysia, and other ethnicities.

Body weight and height of respondents were measured twice using TANITA HD-319 electronic weighing scales (Tanita Corp., Tokyo, Japan) and SECA 213 stadiometer (SECA GmbH \& Co. KG, Hamburg, Germany) to \pm $0.1 \mathrm{~kg}$ and $\pm 0.1 \mathrm{~cm}$, respectively. The average values of body weight and body height were used for BMI-for-age calculation. BMI-for-age z-score was calculated using the AnthroPlus software. The weight status of students was classified into four categories: underweight $(<-2 S D$ z-scores), normal ( $\geq-2 \mathrm{SD}$ to $<+1 \mathrm{SD} \mathrm{z}$-scores), overweight ( $\geq+1 \mathrm{SD}$ to $<+2 \mathrm{SD}$ z-scores), and obese $(\geq+2 \mathrm{SD} \mathrm{z}-$ scores) based on WHO's growth reference for children aged 4 to 19 [15]. Frequency of eating out per week was coded as "more than six times", "three to five times", "one to two times", and "never" based on the multiple choice question: "In a week, how often do you eat out?"

A pretested, self-administered semi-quantitative FFQ for adolescents containing 135 items was developed by panel of experts to obtain information on food consumption based on seven food groups (i.e. cereals or grains, fruits, vegetables, milk or dairy products, meat or poultry or eggs, fish, and legumes). The intake of various food groups per day obtained from the FFQ was translated into the Malaysian Dietary Guideline (MDG) standard serving size [16]. According to the MDG, the recommended intake of cereals or grains was eight to 11 servings per day. For meat or poultry or eggs, the recommended intake was 0.5 to two servings per day, and it is recommended to consume at least three servings of vegetables per day.

\section{Data analysis}

Data analyses were conducted using SPSS version 22 (SPSS IBM, New York, USA). Weighing was applied to take into account the complex study design and nonresponse rate. Descriptive statistics was used to describe the sociodemographic characteristics and frequency of fast-food consumption among adolescents. Factors associated with frequency of fast-food consumption were analysed using complex sample multinomial logistic regression analysis. All statistical analyses were carried out at $95 \%$ confidence interval or $p$-value $<0.05$.

\section{Results}

As shown in Table 1, there were almost equal number of girls and boys in the sample, and majority of the
Table 1 Characteristics of study respondents

\begin{tabular}{|c|c|c|}
\hline Characteristics & $\begin{array}{l}\text { Unweighted } \\
\text { count (n) }\end{array}$ & $\%(95 \% \mathrm{Cl})$ \\
\hline \multicolumn{3}{|l|}{ Age group } \\
\hline $16-18$ years & 5724 & $22.9 \%(21.1-24.7)$ \\
\hline $13-15$ years & 15,615 & $58.0 \%(56.1-59.8)$ \\
\hline $10-12$ years & 5044 & $19.2 \%(17.5-20.9)$ \\
\hline \multicolumn{3}{|l|}{ Sex } \\
\hline Girls & 13,078 & $49.8 \%(47.8-51.9)$ \\
\hline Boys & 13,305 & $50.2 \%(48.1-52.2)$ \\
\hline \multicolumn{3}{|l|}{ Ethnicity } \\
\hline Malay & 17,618 & $60.2 \%(55.4-64.9)$ \\
\hline Indian & 1553 & $6.9 \%(5.6-8.6)$ \\
\hline Indigenous from East Malaysia & 2123 & $10.6 \%(8.7-13.0)$ \\
\hline Other & 452 & $1.8 \%(1.3-2.7)$ \\
\hline Chinese & 4625 & $20.3 \%(16.3-25.1)$ \\
\hline \multicolumn{3}{|l|}{ BMI-for-age } \\
\hline Underweight & 1984 & $7.6 \%(7.1-8.1)$ \\
\hline Overweight & 3962 & $14.9 \%(14.3-15.6)$ \\
\hline Obese & 3433 & $13.1 \%(12.5-13.8)$ \\
\hline Normal & 16,924 & $64.5 \%(63.5-65.5)$ \\
\hline \multicolumn{3}{|l|}{ Locality of schools } \\
\hline Central zone & 3453 & $21.9 \%(18.4-25.7)$ \\
\hline Southern zone & 5319 & $19.5 \%(16.8-22.4)$ \\
\hline East coast zone & 4908 & $17.2 \%(15.1-19.5)$ \\
\hline East Malaysia & 3494 & $17.9 \%(15.2-20.8)$ \\
\hline Northern zone & 7230 & $23.7 \%(20.9-26.7)$ \\
\hline \multicolumn{3}{|c|}{ Frequency of fast food consumption per week } \\
\hline 4-7 days & 3637 & $13.5 \%(12.8-14.2)$ \\
\hline $1-3$ days & 18,232 & $69.3 \%(68.4-70.1)$ \\
\hline 0 day & 4469 & $17.2 \%(16.3-18.2)$ \\
\hline \multicolumn{3}{|l|}{ Eating out per week } \\
\hline$>6$ times & 1299 & $5.1 \%(4.6-5.6)$ \\
\hline $3-5$ times & 3814 & $14.0 \%(13.1-15.0)$ \\
\hline $1-2$ times & 16,708 & $63.2 \%(62.2-64.3)$ \\
\hline Never & 4465 & $17.7 \%(16.5-19.0)$ \\
\hline
\end{tabular}

respondents (60.2\%) were Malay adolescents. Slightly more than half of the respondents $(58.0 \%)$ were of 13 15 years age group, and more than one quarter of them (28.0\%) were overweight $(14.9 \%)$ or obese $(13.1 \%)$. Overall, $13.5 \%$ of the respondents consumed fast-food 4 to 7 days, $69.3 \%$ of the respondents consumed fast-food 1 to 3 days, and $17.2 \%$ of them did not consume fast-food in a typical week. Table 2 shows that the prevalence of adolescents who consumed fast-food 4 to 7 days were significantly higher among Malay adolescents (15.1\%) compared with Indian adolescents (10.7\%) and Chinese 
Table 2 Prevalence of fast-food consumption among adolescents by sociodemographic characteristics, BMI, and eating out behaviour

\begin{tabular}{|c|c|c|c|c|c|c|}
\hline \multirow[t]{3}{*}{ Variables } & \multicolumn{6}{|c|}{ Frequency of fast food consumption per week } \\
\hline & \multicolumn{2}{|c|}{$\begin{array}{l}\text { 4-7 days } \\
(n=3637)\end{array}$} & \multicolumn{2}{|c|}{$\begin{array}{l}1-3 \text { days } \\
(n=18,232)\end{array}$} & \multicolumn{2}{|c|}{$\begin{array}{l}0 \text { day } \\
(n=4467)\end{array}$} \\
\hline & $\%$ & $95 \% \mathrm{Cl}$ & $\%$ & $95 \% \mathrm{Cl}$ & $\%$ & $95 \% \mathrm{Cl}$ \\
\hline \multicolumn{7}{|l|}{ Age group } \\
\hline $16-18$ years & 12.8 & $(11.5-14.2)$ & 69.4 & $(67.8-71.0)$ & 17.8 & $(16.3-19.4)$ \\
\hline $13-15$ years & 13.1 & $(12.3-14.0)$ & 70.0 & $(69.0-71.1)$ & 16.8 & $(15.7-18.0)$ \\
\hline $10-12$ years & 15.4 & $(14.0-17.0)$ & 66.7 & $(64.8-68.6)$ & 17.8 & $(16.3-19.5)$ \\
\hline \multicolumn{7}{|l|}{ Sex } \\
\hline Girls & 13.1 & $(12.2-14.0)$ & 71.3 & $(70.2-72.4)$ & 15.6 & $(14.5-16.8)$ \\
\hline Boys & 13.9 & $(13.0-14.9)$ & 67.3 & $(66.1-68.4)$ & 18.8 & $(17.7-20.0)$ \\
\hline \multicolumn{7}{|l|}{ Ethnicity } \\
\hline Malay & 15.1 & $(14.2-16.0)$ & 70.9 & $(69.9-71.9)$ & 14.0 & $(13.2-15.0)$ \\
\hline Indian & 10.7 & $(9.1-12.6)$ & 69.8 & $(67.2-72.4)$ & 19.5 & $(17.0-22.2)$ \\
\hline Indigenous from East Malaysia & 17.9 & $(15.6-20.4)$ & 65.9 & $(63.2-68.6)$ & 16.2 & $(13.9-18.7)$ \\
\hline Other & 14.3 & $(10.5-19.2)$ & 68.2 & $(64.0-72.2)$ & 17.5 & $(13.5-22.3)$ \\
\hline Chinese & 7.3 & $(6.4-8.3)$ & 66.2 & $(64.2-68.1)$ & 26.5 & $(24.6-28.5)$ \\
\hline \multicolumn{7}{|l|}{ Locality of schools } \\
\hline Central zone & 13.1 & $(11.5-15.0)$ & 70.8 & $(68.9-72.7)$ & 16.1 & $(14.1-18.2)$ \\
\hline Southern zone & 13.1 & $(11.5-14.9)$ & 68.7 & $(67.0-70.4)$ & 18.2 & $(16.3-20.4)$ \\
\hline East coast zone & 15.3 & $(13.9-16.8)$ & 68.4 & $(66.6-70.2)$ & 16.3 & $(14.5-18.2)$ \\
\hline East Malaysia & 17.0 & $(15.2-19.0)$ & 67.0 & $(64.8-69.1)$ & 16.0 & $(14.0-18.2)$ \\
\hline Northern zone & 10.2 & $(9.0-11.4)$ & 70.6 & $(68.8-72.3)$ & 19.2 & $(17.2-21.5)$ \\
\hline \multicolumn{7}{|l|}{ BMI-for-age } \\
\hline Underweight & 12.7 & $(11.0-14.7)$ & 70.7 & $(68.2-73.0)$ & 16.6 & $(14.6-18.9)$ \\
\hline Overweight & 14.0 & $(12.8-15.4)$ & 68.8 & $(67.1-70.5)$ & 17.1 & $(15.7-18.7)$ \\
\hline Obese & 13.9 & $(12.3-15.6)$ & 68.9 & $(66.8-70.9)$ & 17.3 & $(15.5-19.1)$ \\
\hline Normal & 13.4 & $(12.6-14.2)$ & 69.3 & $(68.4-70.2)$ & 17.3 & $(16.3-18.4)$ \\
\hline \multicolumn{7}{|l|}{ Eating out per week } \\
\hline$>6$ times & 26.2 & $(23.1-29.5)$ & 59.0 & $(55.6-62.3)$ & 14.8 & $(12.6-17.4)$ \\
\hline $3-5$ times & 20.1 & $(18.3-22.0)$ & 66.7 & $(64.9-68.5)$ & 13.2 & $(11.7-14.9)$ \\
\hline $1-2$ times & 12.0 & $(11.1-12.8)$ & 73.0 & $(72.1-73.9)$ & 15.0 & $(14.0-16.1)$ \\
\hline Never & 9.9 & $(8.7-11.2)$ & 61.4 & (59.3-63.4) & 28.7 & (26.7-30.8) \\
\hline
\end{tabular}

adolescents (7.3\%). The prevalence of adolescents who consumed fast-food 4 to 7 days were significantly lower among adolescents living in Northern zone (10.2\%) compared with adolescents living in other zones (ranged from 13.1 to $17.0 \%$ ), and those who never eat out (9.9\%) compared with those who eat out at least three times per week (ranged from 20.1 to $26.2 \%$ ). Table 2 also shows that the prevalence of consuming fast food 1 to 3 days was significantly higher among girls (71.3\%) compared with boys (67.3\%), Malays adolescents (70.9\%) compared with Chinese adolescents (66.2\%), those eating out one to three times per week (73.0\%) compared with those eating out more than three times per week (ranged from 59.0 to $66.7 \%)$.

Table 3 shows that adolescents aged 16-18 years old were less likely to consume fast-food 1 to 3 days per week (aOR 0.46, 95\% CI 0.26, 0.82) compared with younger age group of 10-12 years. Girls were more likely to consume fast-food (aOR 1.44, 95\% CI 1.26-1.66 for 4 to 7 days per week and aOR 1.44, 95\% CI 1.301.61 for 1 to 3 days per week) compared with boys. Non-Chinese adolescents (ranged from aOR 2.23 to 4.09) were more likely to consume fast-food 4 to 7 days per week compared with Chinese adolescents. At the same time, Malay adolescents (aOR 1.99, 95\% CI 1.76- 


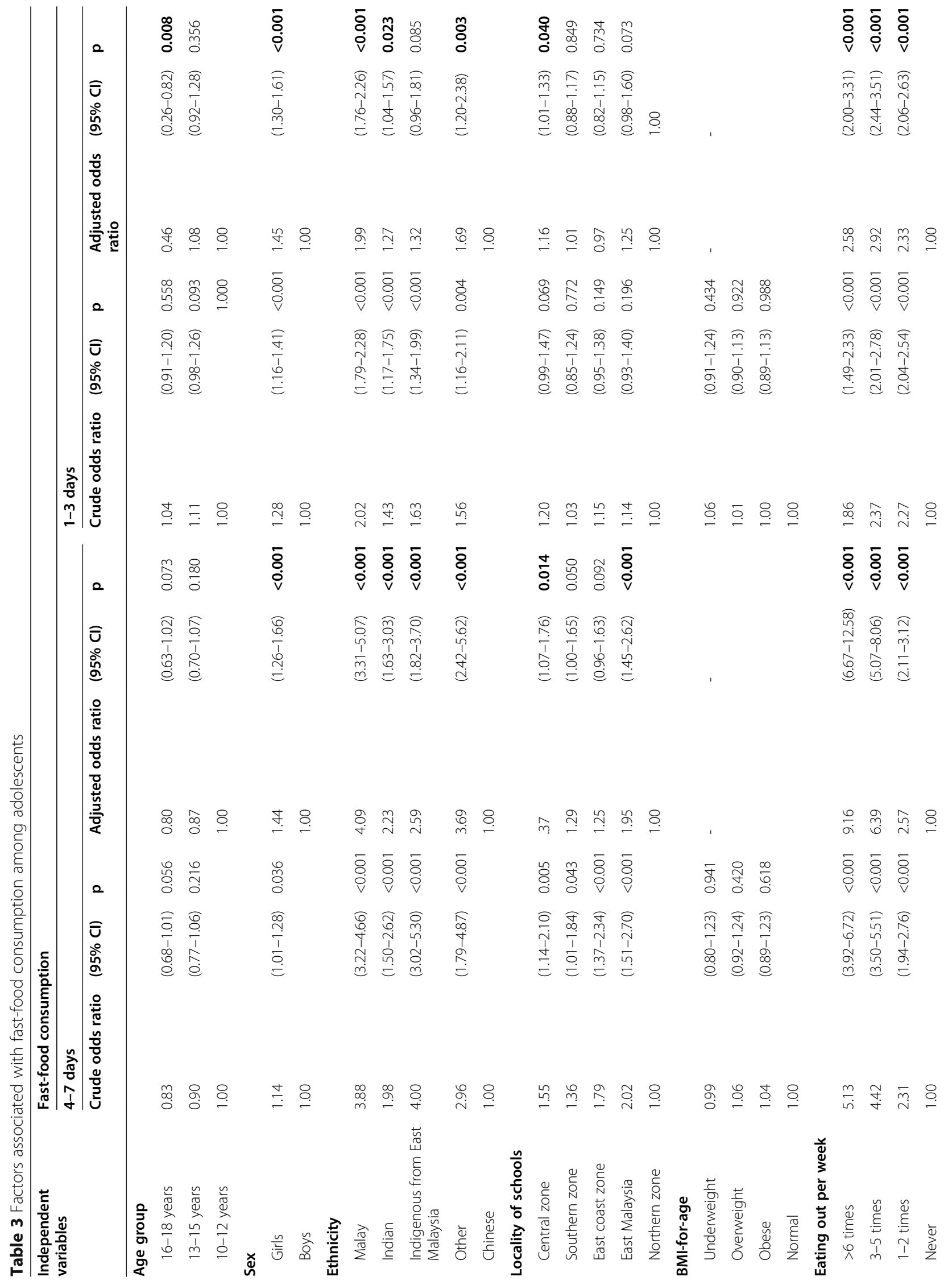




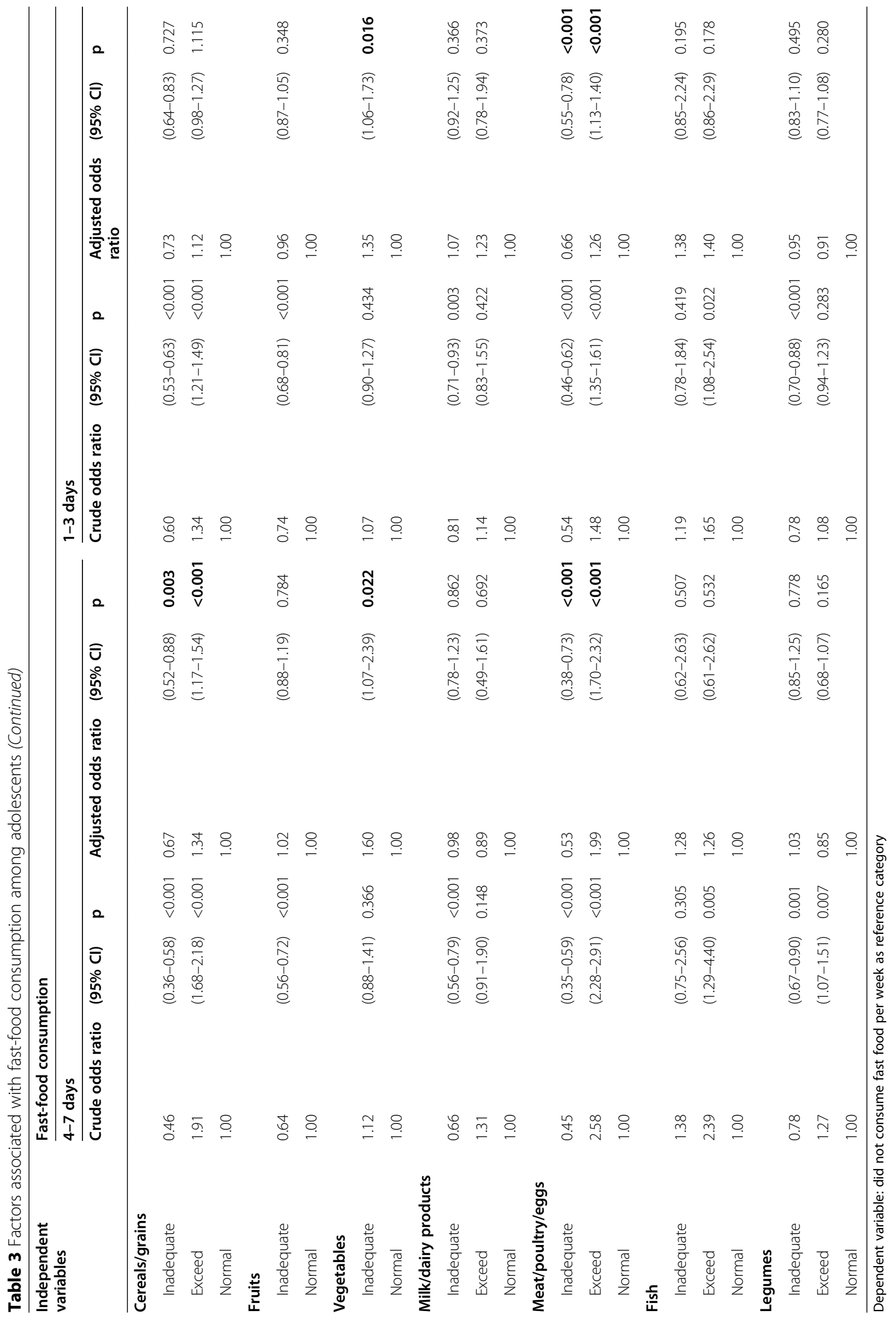


2.26), Indigenous from East Malaysia adolescents (aOR 1.27 , 95\% CI 1.04-1.57), and adolescents with other ethnicities (aOR 1.69, 95\% CI 1.20-2.38) were more likely to consume fast-food 1 to 3 days per week compared with Chinese adolescents.

Adolescents from central zone (aOR1.37, 95\% CI 1.07-1.76) and East Malaysia (aOR 1.95, 95\% CI 1.452.62) were more likely to consume fast food 4 to 7 days per week compared with adolescents from Northern zone. Adolescents who were eating out one to two times, three to five times, and more than six times per week were more likely to consume fast food (aOR 2.57 to 9.16 for 4 to 7 days per week and aOR 2.33 to 2.92 for 1 to 3 days per week) compared with adolescents who did not eat out.

Adolescents who consumed above recommended intake of cereals or grains were more likely to consume fast food 4 to 7 days per week (aOR 1.34, 95\% CI 1.171.54) compared with those who achieved the recommendation. Adolescents who consumed less than recommended intake of vegetables (aOR 1.60, 95\% CI 1.07, 2.39) were more likely to consume fast food 4 to 7 days per week compared with their counterparts with adequate vegetable intake. Adolescents who consumed above recommended intake of meat or poultry or eggs were more likely to consume fast food (aOR 1.99, 95\% CI 1.70-2.32 for 4 to 7 days per week and aOR 1.26, 95\% CI 1.13-1.40) compared with adolescents who achieved the recommended intake of this food group.

\section{Discussion}

This study revealed that older age adolescents (16-18 years old) were less likely to consume fast food compared with the younger age adolescents (10-12 years old). This may be due to older age adolescents experienced physical changes in puberty. The physical changes caused them encountered body shape problems [17]. A previous study revealed that adolescents with body image dissatisfaction were less likely to follow Western dietary pattern but choose a restrictive pattern [18]. Therefore, restriction of fast-food consumption could be part of the diet control behaviour among older adolescents with body image dissatisfaction. This study reported girls were significantly more likely to consume fast food compared with boys. The finding of this study contradicts with other studies $[19,20]$. A previous study found that adolescent girls were more likely to visit fastfood outlets in special days to meet with friends or family than boys especially in city centres [21]. Another previous study disclosed that the main reasons of adolescent girls consuming fast food were enjoying the taste of fast food and favouring the convenience of the fast-food restaurants [22]. However, there is no evidence found to explain the preference of girls to consume fast food compared with boys. This study suggests future research to investigate about the gender preferences and perception of fast-food consumption which are needed in order to fill this research gap.

In this study, ethnicity was found to be significantly associated with fast-food consumption. Non-Chinese adolescents were more likely to consume fast food than Chinese adolescents. The findings from this study are also in line with a previous Malaysian study that found Chinese adolescents consumed healthier food than Malay adolescents [21]. Two possible reasons for the ethnic differences in fast-food consumption were identified. Firstly, Chinese adolescents are less likely to be influenced by unhealthy food advertising on television compared with other ethnicities since their childhood [23]. Secondly, previous study revealed that traditional Chinese parenting styles are more concerned with healthy eating practices among their children [24]. For instance, most Chinese mothers would restrict certain unhealthy foods and encourage balanced food intake for health reasons [24].

Adolescents from the Central Zone and East Malaysia were significantly more likely to consume fast food compared with those from the Northern Zone. Availability of fast-food restaurants nearby school areas and neighbourhoods were crucial factors contributing to fast-food consumption habits among adolescents [25]. In Malaysia, fast-food restaurants are always available in areas with higher density of population. Therefore, adolescents who live in Northern Zone with lower density of population [26] may have less frequent access to fastfood than adolescents from the Central Zone. Interestingly, fast-food consumption was also high in East Malaysia although most of the residential areas there were of lower density of population. A possible reason may be that there is rapid expansion of franchise fastfood chain and home-grown fast-food chain in East Malaysia after implementing the Franchise Development Program in 1992 [27]. This programme may change the dietary habits of adolescents and younger adults in East Malaysia. Future study is suggested to investigate fastfood consumption pattern in East Malaysia to better understand the fast-food intake behaviour among adolescents in East Malaysia.

The findings indicate that fast-food consumption among adolescents was not associated with BMI for age. This is in line with previous studies $[11,28,29]$, although there were studies that demonstrated otherwise among adults $[9,10]$. This could be due to not only fastfood consumption, but also their overall dietary intake being the main contributor to being overweight or obese among adolescents [29]. For example, products such as sugary beverages and chips from retail food stores contain similar levels of fat and sugar as in fast food [29]. 
Another possible explanation may be that overweight or obese adolescents tend to under-report the frequency of fast-food intake [30] due to the possibility of social desirability bias, as most people know that fast food is unhealthy food. However, other related factors that could confound the relationship between fast-food consumption and BMI, such as physical activity and body image perception, were not investigated in this study $[17,31]$.

In this study, fast-food consumption was associated with frequency of eating out per week. Eating out of home is increasingly common among Malaysian households since 1990s [32, 33] along with increasing household income and lifestyle changes. A Malaysian study found that $91.2 \%$ of adolescents aged between 13 and 14 years old have family meal away from home at least once a week in an urban area in Selangor [33]. Households with higher income and in urban areas have higher probability of dining away from home for all ethnicities in Malaysia [34]. The local study also reported that, among adolescents with having meal away from home habit, $41.6 \%$ of them visited fast-food outlets when they were eating outside with their families [33]. Our study suggests that eating out increases the probability of eating fast food regardless of eating with friends or family members among adolescents because fast-food outlets are considered one of the common choices for eating out. Therefore, knowledge, skill, and motivation to opt for healthy food are needed within the households in order to promote healthy eating away from home among adolescents.

This study also revealed that consumption of cereals or grains, vegetables, and meat or poultry or eggs were factors significantly associated with fast-food consumption. Adolescents who consumed excessive cereals or grains (more than 11 servings per day) and meat or poultry or eggs (more than two servings per day) were significantly more likely to consume fast food. In addition, those who consumed inadequate vegetables (less than three servings per day) were also more likely to consume fast food [16]. This finding is reasonable because chicken-based, bread-based, and fish-based fast food were the favourite fast-food items among young Malaysians [35]. This study suggests that adolescents who consumed fast food often linked to imbalanced dietary intake which may increase the risk of having non-communicable diseases among adolescents [21].

The major strength of this study is the use of a nationally representative sample to demonstrate findings applicable to the Malaysian adolescent population. In addition, the findings of this study provide new insights to the existing literature on dietary behaviour among adolescents in Malaysia. Fast-food outlets are expanding to rural areas in the recent years. This study also recruited adolescents from remote zones such as East Malaysia, adding new information on dietary behaviours of adolescents in the remote areas. There are a few limitations in this study. First, this is a cross-sectional study; therefore, it is not possible to establish cause and effect relationship in this study. Second, owing to self-recall of fastfood consumption, the data may contain self-recall bias. It is possible that frequency of fast-food consumption being over- or under-reported in this study.

\section{Conclusion}

In conclusion, significant factors associated with fastfood consumption were age, sex, ethnicity, locality of schools, frequency of eating out, imbalanced intake of cereals or grains, meat or poultry or eggs, and inadequate vegetables intake. This study provides evidencedbased findings to help policy makers and professionals in designing more effective strategies and programmes to promote healthy food choices among adolescents in Malaysia. Despite the Ministry of Health Malaysia initiated a healthy eating strategy in fast-food restaurants to provide healthier food options to the public [36], all relevant committees should strengthen the existing strategy through reformulating fast-food products to reduce fat, salt, and sugar content as fast food is commonly consumed among adolescents.

\section{Abbreviations}

BMI: Body mass index; FFQ: Food frequency questionnaire; MDG: Malaysian Dietary Guidelines; NSNS: National School-Based Nutrition Survey; WHO: World Health Organization

\section{Acknowledgements}

The authors are grateful to the respondents and the research team members of the National School-based Health Survey 2012 who made this survey a success. We also thank the Director General of Health at the Ministry of Health Malaysia for the permission to publish this manuscript.

\section{Authors' contributions}

CSM and KCC designed the outline of the manuscript and drafted the manuscript. LKH contributed to the outline of the manuscript and decided the methods for statistical analyses. CYY analysed the data and proof read the manuscript. LKK and TCH drafted the manuscript and revised the manuscript. AB and NSAA contributed to critical review of the manuscript. The authors read and approved the final manuscript.

\section{Funding}

The fund of this survey was supported by the Ministry of Health Malaysia.

\section{Availability of data and materials}

The dataset that supports the findings of this study belongs to the Ministry of Health Malaysia.

\section{Declarations}

Ethics approval and consent to participate

Ethical approval for the National School-based Nutrition Survey was obtained from the Medical Research and Ethics Committee, Ministry of Health Malaysia, and Ministry of Education Ethics Committee (NMRR-11-974-10527). Only students with informed consent form were recruited into this survey.

Competing interests

The authors declare that they have no competing interests. 


\section{Author details}

'Centre for Nutrition Epidemiology Research, Institute for Public Health, National Institutes of Health, Ministry of Health Malaysia, No.1, Jalan Setia Murni U13/53, Section U13, Setia Alam, 40170 Shah Alam, Selangor, Malaysia. ${ }^{2}$ Special Research Centre, Institute for Medical Research, National Institutes of Health, Ministry of Health Malaysia, Kuala Lumpur, Malaysia. ${ }^{3}$ Centre for Family Health Research, Institute for Public Health, National Institutes of Health, Ministry of Health Malaysia, Shah Alam, Selangor, Malaysia. ${ }^{4}$ Sector for Biostatistics and Data Repository, National Institutes of Health, Ministry of Health Malaysia, Shah Alam, Selangor, Malaysia. ${ }^{5}$ Centre for Occupation Health Research, Institute for Public Health, National Institutes of Health, Ministry of Health Malaysia, Shah Alam, Selangor, Malaysia. ${ }^{6}$ Biomedical Research Management, Strategy and Innovation Unit, Institute for Medical Research, National Institutes of Health, Ministry of Health Malaysia, Shah Alam, Selangor, Malaysia.

Received: 26 February 2019 Accepted: 25 June 2021

Published online: 16 July 2021

\section{References}

1. Dictionary C. Fast food [19/05/2020]. Available from: https://dictionary.ca mbridge.org/dictionary/english/fast-food.

2. Noor Ml. The nutrition and health transition in Malaysia. Public Health Nutr. 2002;5(1a):191-5. https://doi.org/10.1079/PHN2001293.

3. Soon JM, Tee ES. Changing trends in dietary pattern and implications to food and nutrition security in association of Southeast Asian Nations (ASEA N). Int J Food Sci Nutr. 2014;3(4):259-69. https://doi.org/10.11648/j.ijnfs.2014 0304.15.

4. Economic Census in 2016. Putrajaya: Department of Statistic Malaysia. 2017.

5. Sebastian RS, Enns CW, Goldman JD. US adolescents and MyPyramid: associations between fast-food consumption and lower likelihood of meeting recommendations. J Am Diet Assoc. 2009;109(2):226-35. https:// doi.org/10.1016/j.jada.2008.10.053.

6. Lipsky LM, Haynie DL, Liu D, Chaurasia A, Gee B, Li K, et al. Trajectories of eating behaviors in a nationally representative cohort of US adolescents during the transition to young adulthood. Int J Behav Nutr Phys Act. 2015 12(1):138. https://doi.org/10.1186/s12966-015-0298-x.

7. Todd A, Street S, Ziviani J, Byrne N, Hills A. Overweight and obese adolescent girls: the importance of promoting sensible eating and activity behaviors from the start of the adolescent period. Int I Environ Res Public Health. 2015;12(2):2306-29. https://doi.org/10.3390/ijerph120202306.

8. Mohr P, Wilson C, Dunn K, Brindal E, Wittert G. Personal and lifestyle characteristics predictive of the consumption of fast foods in Australia. Public Health Nutr. 2007;10(12):1456-63. https://doi.org/10.1017/S13 68980007000109.

9. Whitton C, Ma Y, Bastian AC, Chan MF, Chew L. Fast-food consumers in Singapore: demographic profile, diet quality and weight status. Public Health Nutr. 2014:17(8):1805-13. https://doi.org/10.1017/S1368980013001997.

10. Black JL, Billette J-M. Fast food intake in Canada: differences among Canadians with diverse demographic, socio-economic and lifestyle characteristics. Can J Public Health. 2015;106(2):e52-e8. https://doi.org/10.1 7269/CJPH.106.4658.

11. Xue $H$, Wu Y, Wang $X$, Wang $Y$. Time trends in fast food consumption and its association with obesity among children in China. PLoS One. 2016;11(3): e0151141. https://doi.org/10.1371/journal.pone.0151141.

12. Abdullah NN, Mokhtar MM, Bakar MHA, Al-Kubaisy W. Trend on fast food consumption in relation to obesity among selangor urban community. Procedia Soc Behav Sci. 2015;202:505-13. https://doi.org/10.1016/j.sbspro.2015.08.189.

13. Chong KH, Wu SK, Noor Hafizah Y, Bragt MC, Poh BK, Group SMS. Eating habits of Malaysian children: findings of the South East Asian Nutrition Surveys (SEANUTS). Asia Pac J Public Health. 2016:28(5 suppl):59S-73S.

14. Yusoff F, Saari R, Naidu BM, Ahmad NA, Omar A, Aris T. Methodology of the national school-based health survey in Malaysia, 2012. Asia Pac J Public Health. 2014;26(5_suppl):9S-17S.

15. WHO. ANTHROPLUS for personal computers. Geneva: Manual: software for assessing growth of the world's children and adolescents; 2009. [updated Accessed December 2016]. Available from: Retrieved from: http://www.who. int/growthref/tools/en/

16. Technical Working Group on Nutrition. Malaysian dietary guidelines. Putrajaya: National Coordinating Committee on Food and Nutrition, Ministry of Health Malaysia; 2010.
17. Khor GL, Zalilah MS, Phan YY, Ang M, Maznah B, Norimah AK. Perceptions of body image among Malaysian male and female adolescents. Singapore Med J. 2009;50(3):303.

18. Ribeiro-Silva RC, Fiaccone RL, Conceição-Machado MEPD, Ruiz AS, Barreto ML, Santana MLP. Body image dissatisfaction and dietary patterns according to nutritional status in adolescents. J Pediatr. 2018:94(2):155-61. https://doi. org/10.1016/j.jped.2017.05.005.

19. Denney-Wilson E, Crawford D, Dobbins T, Hardy L, Okely AD. Influences on consumption of soft drinks and fast foods in adolescents. Asia Pac J Clin Nutr. 2009;18(3):447-52.

20. Nasreddine L, Chamieh MC, Ayoub J, Hwalla N, Sibai A-M, Naja F. Sex disparities in dietary intake across the lifespan: the case of Lebanon. Nutr J. 2020;19(1):1-18.

21. Abdullah N-F, Teo PS, Foo LH. Ethnic differences in the food intake patterns and its association factors of adolescents in Malaysia; 2016

22. ALFaris NA, Al-Tamimi JZ, Al-Jobair MO, Al-Shwaiyat NM. Trends of fast food consumption among adolescent and young adult Saudi girls living in Riyadh. Food Nutr Res. 2015;59(1):26488.

23. Ng SH, Kelly B, Se CH, Sahathevan S, Chinna K, Ismail MN, et al. Reading the mind of children in response to food advertising: a cross-sectional study of Malaysian schoolchildren's attitudes towards food and beverages advertising on television. BMC Public Health. 2015;15(1):1047. https://doi. org/10.1186/s12889-015-2392-z.

24. Zhou N, Cheah CS, Van Hook J, Thompson DA, Jones SS. A cultural understanding of Chinese immigrant mothers' feeding practices. A qualitative study. Appetite. 2015;87:160-7. https://doi.org/10.1016/j.appet.2014.12.215.

25. Joo S, Ju S, Chang H. Comparison of fast food consumption and dietary guideline practices for children and adolescents by clustering of fast food outlets around schools in the Gyeonggi area of Korea. Asia Pac J Clin Nutr. 2015;24(2):299-307. https://doi.org/10.6133/apjen.2015.24.2.03.

26. Ali N, Abdullah MA. The food consumption and eating behaviour of Malaysian urbanites: issues and concerns. Malaysia J Soc Space. 2012;8(6) Retrieved from: http://journalarticle.ukm.my/5608/1/14.geografia-sept\%252 02012-azlan-si-ppspp-ed\%2520am1.pdf.

27. Ibrahim ZB. The development of franchise fast food restaurant in Malaysia: the views of consumer on Kuching market [E-Thesis]. Sarawak: Universiti Malaysia Sarawak; 2004.

28. Braithwaite I, Stewart AW, Hancox RJ, Beasley R, Murphy R, Mitchell EA, et al. Fast-food consumption and body mass index in children and adolescents: an international cross-sectional study. BMJ Open. 2014;4(12):e005813. https://doi.org/10.1136/bmjopen-2014-005813.

29. Poti JM, Duffey KJ, Popkin BM. The association of fast food consumption with poor dietary outcomes and obesity among children: is it the fast food or the remainder of the diet? Am J Clin Nutr. 2013;99(1):162-71. https://doi. org/10.3945/ajen.113.071928

30. Patterson R, Risby A, Chan M-Y. Consumption of takeaway and fast food in a deprived inner London Borough: are they associated with childhood obesity? BMJ Open. 2012;2(3):e000402. https://doi.org/10.1136/bmjopen-2 011-000402

31. Rezali FW, Chin YS, Yusof M, Nisak B. Obesity-related behaviors of Malaysian adolescents: a sample from Kajang district of Selangor state. Nutr Res Pract. 2012;6(5):458-65. https://doi.org/10.4162/nrp.2012.6.5.458.

32. Islam GN, Yew TS, Abdullah NMR, Noh KM. Household expenditure on food away from home by type of meal in Malaysia. Editorial Board. 2010;18:28594.

33. Cynthia J, Zalilah MS, Lim MY. Relationship between family meals away from home and nutritional status of adolescents. Malays J Nutr. 2013;19(1): 25-35.

34. Tan AK. Demand for food-away-from-home in Malaysia: a sample selection analysis by ethnicity and gender. J Foodserv Bus Res. 2010;13(3):252-67. https://doi.org/10.1080/15378020.2010.500257.

35. Habib FQ, Abu Dardak R, Zakaria S. Consumers' preference and consumption towards fast food: evidences from Malaysia. Bus Manage Quaterly Rev. 2011; 2(1):14-27 Retrieved from: https://ir.uitm.edu.my/id/eprint/880/.

36. Technical Working Group on Nutrition. National Plan of Action for Nutrition of Malaysia III 2016-2025. Putrajaya: National Coordinating Committee on Food and Nutrition, Ministry of Health Malaysia; 2016.

\section{Publisher's Note}

Springer Nature remains neutral with regard to jurisdictional claims in published maps and institutional affiliations. 